\title{
HEPATOCURATIVE POTENTIALS OF METHANOL EXTRACTS/FRACTIONS OF Tapinanthus bangwensis AND Moringa oleifera ON CARBON TETRACHLORIDE- INDUCED HEPATOTOXICITY IN WISTAR RATS
}

\author{
${ }^{1 *}$ Ihegboro, G. O., ${ }^{2}$ Alhassan, A. J., ${ }^{3}$ Afor, E., ${ }^{1}$ Ononamadu, C. J., ${ }^{1}$ Owolarafe, T. A., \\ ${ }^{2}$ Imam, A. A., Salawu, K., ${ }^{2}$ Ibrahim, A., ${ }^{2}$ Sule, M. S. \\ ${ }^{1}$ Department of Biochemistry and Forensic Science, Faculty of Sciences, Nigeria Police Academy, Wudil, Kano. \\ ${ }^{2}$ Department of Biochemistry, Faculty of Basic Medical Sciences, Bayero University, Kano. ${ }^{3}$ Department of Chemical \\ Science, School of Mathematics and Science, Yaba College of Technology, Yaba. \\ Authors' email addresses: *IGO-goihegboro@yahoo.com, AAJ-ajalhassan.bch@buk.edu.ng, AE- \\ aforemman.65@gmail.com, OCJ-ononamaducj@polac.edu.ng, OTA-taowolarafe@gmail.com, IAA- \\ aaimam.bch@buk.edu.ng, SK-kailani.salawu@gmial.com,IA-aibrahim.bch@buk.edu.ng, SMS-mssule.bch@buk.edu.ng. \\ *Corresponding Author-Tel.:+2347031149957.
}

(Received: $17^{\text {th }}$ September, 2019; Accepted: 29 ${ }^{\text {th }}$ April, 2020)

ABSTRACT

\begin{abstract}
Bioaccumulation of toxic substances in liver poses a serious threat to its functionality and consequently leads to damage/injury. Medicinal plants have been reported to be effective in the treatment and management of various diseases. The present study is aimed at evaluating the hepatocurative potentials of Tapinanthus bangwensis and Moringa oleifera on carbon tetrachloride-induced hepatotoxicity in Wistar rats. Atomic absorption spectroscopy (AAS) and ultraviolet-visible spectrophotometry were respectively used to assay for mineral elements and antioxidant activity of methanol extracts/fractions of T. bangwensis and M. oleifera. Concentrations of potassium in methanol extract of $M$. oleifera (MeCE 2) and magnesium in T. bangwensis (MeCE 1) were found to be significantly high $(\mathrm{p}<0.05)$. Concentrations of trace elements were low in the range of $0.07 \mathrm{mg} / \mathrm{kg}$ to 0.60 $\mathrm{mg} / \mathrm{kg}$. The in vitro lipid peroxidation assay showed that ethylacetate fraction and acetone fraction of T. bangwensis (ETF 1 and ACF 1) respectively exhibited the strongest and lowest antioxidant activity compared to other extracts/fractions. Oral administration of methanol extracts/fractions of $T$. bangwensis and $M$. oleifera significantly increased superoxide dismutase (SOD) and catalase (CAT) activities, increased glutathione (GSH) level and decreased malondialdehyde (MDA) level. The liver function indices (or liver biomarkers) such as aspartate aminotransferase (AST), alanine aminotransferase (ALT), alkaline phosphatase (ALP), albumin, total protein, total and conjugated bilirubin and lipid parameters (low density lipoprotein (LDL-c), cholesterol and triglyceride) were also significantly reduced. However high density lipoprotein (HDL-c) increased in the groups induced and treated with methanol extracts/fractions of T. bangwensis and M. oleifera compared to the group induced but untreated. It can be concluded that the plants possessed hepatocurative potential against $\mathrm{CCl}_{4}$ induced hepatotoxicity in Wistar rats
\end{abstract}

Keywords: Bioaccumulation, Hepatotoxicity, Liver biomarkers, Moringa oleifera Tapinanthus bangwensis

\section{INTRODUCTION}

The liver performs several functions such as regulatory, digestive, storage, production and detoxification functions, to mention but a few ( $\mathrm{Si}$ Tayeb et al., 2010) It is however susceptible to damage by toxic substances such as carbon tetrachloride and other hepatotoxic agents (Ginanaprakash et al., 2010) thereby resulting in liver disease which is one of the world's ravaging problem (Adewusi and Afolayan, 2010). The highly toxic carbon trichloromethyl and its derivatives produced via cytochrome $\mathrm{P}_{450}$ enzyme activity causes hepatocytic damage characterized by tissue loss, loss of metabolic enzyme activation, inhibition of protein and lipoprotein secretion and decreased liver enzymes of oxidative stress and prevents its regenerative capacity (Grish et al., 2009; Khan et al., 2009; Ajiboye, 2010; Xu et al., 2011; El-Sayed et al., 2015). Modern medicine used in the treatment and management of liver diseases is still effective however they are characterized by various degrees of adverse side effects (Wagh et al., 2010). Medicinal plants have been shown to be more effective and efficacious in disease management especially in developing countries like Nigeria owing to the significant concentration of phytochemical compounds present in them (Kumar et al., 2011). Tapinanthus bangwensis and Moringa oleifera have been reported to be ethnopharmacologically beneficial against wide range 
of diseases hence their use in this study. Tapinanthus bangwensis is an evergreen obligate semi-parasitic plant growing on citrus tree and belongs to the Loranthaceae family. It is of Africa origin and as such it is also called African mistletoe. The English acronyms for the plant are "all heal tree, "bird lime" or "tree of life" while various ethnic groups in Nigeria such as Hausa call it Kauci (Kanchi), Yoruba-, Afomo onisana and IgboAwurusie (or Apari). Its ethno-medicinal benefits include anti-inflammatory, anti-microbial, anticancer, hypotensive and hypoglycemic effects (Ihegboro et al., 2018). Moringa oleifera is referred to as miracle trees and belong to the Moringaceae family. The other English acronyms are drumstick tree, horseradish tree, benzoil tree and mother's best friend. In Nigeria, the Hausas call it Bagaruar maka (masar), Rimin nasara (turawa) or popularly called Zogale, Yoruba-Idagbo monoye (tree that grows crazily) and the Igbos- Okochi egbu (cannot be killed by drought) (Stevens et al., 2015). It is a fastgrowing, drought-resistant and deciduous tree with origin from Haimalayans in India and widely cultivated in tropical and subtropical areas with wide range of beneficial effects (Sinha et al., 2011). Such effects include its antitumor, antipyretic, anti-inflammatory, antimicrobial, antiretroviral, antidiabetic and antioxidant; as well as its cardiovascular and haematological properties (Anwar and Rashid, 2007; Walter, 2011; Pallwell, 2011; Nikkon, 2013, Onyekal et al., 2013). Therefore the present study focussed on evaluating the mineral composition, antioxidant activity and in vivo hepatocurative potentials of crude methanol extracts/fractions of T. bangwensis and $M$. oleifera leaves on carbon tetrachlorideinduced hepatotoxicity in Wistar rats.

\section{MATERIALS AND METHODS Plant Materials}

Fresh leaves of T. bangwensis were obtained from Mushin market in Lagos and identified by $\mathrm{Mr}$ Adeleke, Department of Pharmagnosy, University of Lagos. The plant voucher number (LUH 3856) was deposited in the University's herbarium while $M$. oleifera leaves were obtained from the Co-ordinator's lodge, Nigeria Police Academy, Wudil, Kano and was identified in the Department of Botany, Bayero University Kano. M. oleifera with voucher number (BUH 4123) was deposited in the University's herbarium. The leaves of the plants were washed with distilled water and dried for 5 days under dry climatic condition and the dried leaves were pulverized into a fluffy mass ready for extraction.

\section{Extraction of Plant Materials}

A $2.15 \mathrm{~kg}$ powdered mass each of T. bangwensis and M. oleifera was extracted with $10 \mathrm{~L}$ of $100 \%$ methanol using cold maceration method. The filtrates were then concentrated through evaporation at room temperature for 2 days. The mass yield of methanol crude extracts of $T$. bangwensis (MeCE1) and M. oleifera (MeCE 2) were $187.5 \mathrm{~g}(8.71 \%)$ and $209.0 \mathrm{~g}(9.73 \%)$ respectively.

\section{Solvent-Partitioned Extraction}

The concentrated crude methanol extracts of $T$. bangwensis and $M$. oleifera were further fractionated using separation funnel. The solution mixture was ethylacetate-water and acetone-water in 3:2 respectively. A $60 \mathrm{~g}$ of the methanol extract of $T$. bangwensis was shaken vigorously with the resulting solution in the separation funnel and then allowed to stand. Two layers were observed, ethylacetate and aqueous-methanol layers respectively. The ethylacetate layer was collected, dried and labelled as ETF $1(14.45 \mathrm{~g})$. For the acetone fraction (ACF 1), $50 \mathrm{~g}$ of methanol extract of T. bangwensis was shaken vigorously with the resulting solution in the separation funnel. Acetone and aqueousmethanol layers were observed respectively. The acetone portion was collected, dried and labelled as ACF 1 (9.37 g). The same procedure as described for obtaining fractions of $T$. bangwensis was employed to obtain $M$. oleifera fractions. The mass yield of ethylacetate fraction (ETF 2) and acetone fraction (ACF 2) of M. oleifera were $8.02 \mathrm{~g}$ and $7.45 \mathrm{~g}$ respectively.

\section{Determination of Mineral Elements' Compositions}

The method described by Soylak et al., (2004) was used to determine the concentration of sodium $(\mathrm{Na})$, potassium $(\mathrm{K})$, magnesium $(\mathrm{Mg})$, manganese ( $\mathrm{Mn})$, copper ( $\mathrm{Cu})$, zinc $(\mathrm{Zn})$ and iron $(\mathrm{Fe})$ in the crude methanol extracts/fractions of $T$. bangwensis and $M$. oleifera using atomic absorption spectroscopy. $2 \mathrm{~g}$ of the extract/fraction in a crucible was heated at $450{ }^{\circ} \mathrm{C}$ for 1 hour and then ashed for 8 hours until a white ash residue was obtained. $15 \mathrm{ml}$ of concentrated 
$\mathrm{HNO}_{3}(25 \% \mathrm{v} / \mathrm{v}), 8 \mathrm{ml}$ of concentrated $\mathrm{HCl}$ and 4 $\mathrm{ml}$ of $30 \% \mathrm{H}_{2} \mathrm{O}_{2}$ were added. The mixture was filtered and the filtrate diluted with distilled water to $100 \mathrm{ml}$. The absorbance of the solution was measured at specific wavelength for each element using Buck Scientific Atomic Spectrophotometer VGP system model 210.

\section{Experimental Animals}

Forty apparently healthy male Wistar rats weighing averagely $100 \mathrm{~g}$ were used and they were maintained under standard laboratory conditions. The rats were acclimatized for 2 weeks under standard environmental conditions at $25{ }^{\circ} \mathrm{C}$ with 12:12 hour light-dark cycle in airy plastic cages. They were fed with rat feed and distilled water.

\section{Experimental Design}

The rats were divided into eight (8) groups with five (5) rats in each group:

Group A: Rats received feed and water (Normal control group)

Group B: Rats induced with a dose of $120 \mathrm{mg} / \mathrm{kg}$ bwt of $\mathrm{CCl}_{4}$ in olive oil intraperitoneally (Positive control group)

Group C: Rats induced with a dose of $120 \mathrm{mg} / \mathrm{kg}$ bwt of $\mathrm{CCl}_{4}$ and then administered with 250 $\mathrm{mg} / \mathrm{kg}$ bwt of crude methanol extract of $T$. bangwensis daily for 7 days

Group D: Rats induced with a dose of $120 \mathrm{mg} / \mathrm{kg}$ bwt of $\mathrm{CCl}_{4}$ and then administered with 250 $\mathrm{mg} / \mathrm{kg}$ bwt of ethylacetate fraction of $T$. bangwensis daily for 7 days

Group E: Rats induced with a dose of $120 \mathrm{mg} / \mathrm{kg}$ bwt of $\mathrm{CCl}_{4}$ and then administered with 250 $\mathrm{mg} / \mathrm{kg}$ bwt of acetone fraction of $T$. bangwensis daily for 7 days.

Group F: Rats induced with a dose of $120 \mathrm{mg} / \mathrm{kg}$ bwt of $\mathrm{CCl}_{4}$ and then administered with 250 $\mathrm{mg} / \mathrm{kg}$ bwt of crude methanol extract of $M$. oleifera daily for 7 days.

Group G: Rats induced with a dose of $120 \mathrm{mg} / \mathrm{kg}$ bwt of $\mathrm{CCl}_{4}$ and then administered with 250 $\mathrm{mg} / \mathrm{kg}$ bwt of ethylacetate fraction of $M$. oleifera daily for 7 days.

Group H: Rats induced with a dose of $120 \mathrm{mg} / \mathrm{kg}$ bwt of $\mathrm{CCl}_{4}$ and then administered with 250 $\mathrm{mg} / \mathrm{kg}$ bwt of acetone fraction of $M$. oleifera daily for 7 days.

\section{In Vitro Lipid Peroxidation Assay}

The in vitro lipid peroxidation assay of Buege and Aust, (1978) was adopted. Freshly excised rat liver was sliced and homogenized in cold $150 \mathrm{mM}$ $\mathrm{KCl}-$ Tris $-\mathrm{HCl}$ buffer. The reaction mixture contained $0.1 \mathrm{ml}$ liver homogenate, Tris- $\mathrm{HCl}$ buffer (20 mM at pH 7.0), $2 \mathrm{mM} \mathrm{FeCl}, 10 \mathrm{mM}$ ascorbic acid and $0.5 \mathrm{ml}$ plant extract (25-250 $\mu \mathrm{g} / \mathrm{ml}$ ) in a final volume of $1.0 \mathrm{ml}$. The reaction mixture was incubated at $37^{\circ} \mathrm{C}$ for 1 hour. The incubated reaction mixture was mixed with $2 \mathrm{ml}$ of TBA-TCA-HCl reagent $[(0.375 \% \quad \mathrm{w} / \mathrm{v}$ thiobarbituric acid (TBA); $15 \% \mathrm{w} / \mathrm{v}$ trichloroacetic acid (TCA) and $0.25 \mathrm{~N}$ hydrochloric acid ( $\mathrm{HCl})$ ] and heated in a boiling water bath for 15 minutes. After cooling, the solution was centrifuged at $3000 \mathrm{rpm}$ for 5 minutes. Lipid peroxidation was measured as malondialdehyde (MDA) at $535 \mathrm{~nm}$.

$\%$ inhibition $=\frac{\text { Absorbance of control }- \text { Absorbance of extract }}{\text { Absorbance of control }} \times 100$

\section{Collection and Storage of Blood Samples}

After the 7th day of oral administration of crude methanol extracts/fractions of T. bangwensis and M. oleifera, the rats were fasted overnight for 12 hours. The rats were anaesthetized using chloroform and blood collected through the jugular vein at the neck region. The blood samples were centrifuged at $3000 \mathrm{rpm}$ for 5 mins and the serum obtained was stored at $4{ }^{\circ} \mathrm{C}$ before being used for various liver function indices and lipid profile analyses.

\section{Determination of Liver Biomarkers Assays}

The liver biomarkers of oxidative stress such as superoxide dismutase (SOD), catalase (CAT) activity and glutathione (GSH) level were evaluated by standard biochemical protocols.

\section{Determination of Liver Function Indices}

The liver function indices such as alanine aminotransferase (ALT), alkaline phosphatase (ALP), aspartate aminotransferase (AST) activities and albumin (ALB), total bilirubin (T.Bil), conjugated bilirubin (C.Bil) and total protein (TP) levels and lipid profile such as low density lipoprotein (LDL-c), high density lipoprotein (HDL-c), cholesterol and triglyceride were evaluated using standard protocols and assay kits 
from Randox Laboratories Limited, United Kingdom.

\section{Liver Histology}

The method of Million et al. (2019) was followed. After the rats were sacrificed, livers were excised and fixed in 10\% formalin saline solution for 72 hours, dehydrated through ascending alcohol gradient (50, 70, 90 and 100\%) and cleared in two changes of xylene I and II and embedded in paraffin wax. Serial transverse section of $4-5 \mu \mathrm{m}$ thickness was prepared using the Leica microtome and then stained with haematoxylin and eosin $(\mathrm{H}$ $\& \mathrm{E})$. The samples were then viewed under light microscope and observations recorded.

\section{Statistical Analysis}

The data obtained were analyzed using one way ANOVA (Analysis of Variance). All data were expressed as Mean \pm SD and the significant difference was considered at $\mathrm{p}<0.05$

\section{RESULTS}

\section{In vitro Antioxidant Activity}

The result revealed that ethylacetate fraction of $T$. bangwensis (ETF 1) exhibited the strongest antioxidant activity $\left(\mathrm{IC}_{50}=3.64 \pm 0.12 \mu \mathrm{g} / \mathrm{ml}\right)$ while acetone fraction of $T$. bangwensis (ACF 1) exhibited the lowest antioxidant activity $\left(\mathrm{IC}_{50}=\right.$ $4.75 \pm 0.13 \mu \mathrm{g} / \mathrm{ml}$ ) when compared to other extracts/fractions. However ascorbic acid exhibited the strongest antioxidant activity $(3.40 \pm$ $0.39 \mu \mathrm{g} / \mathrm{ml}$ ) compared to the extracts/fractions of the plants (Table 1$)$.

\section{Mineral Element Composition}

Table 2 showed the concentration of sodium $(\mathrm{Na})$, potassium $(\mathrm{K})$, magnesium $(\mathrm{Mg})$, manganese $(\mathrm{Mn})$, copper $(\mathrm{Cu})$, zinc $(\mathrm{Zn})$ and iron (Fe) present in the methanol extracts/fractions of $T$. bangwensis and $M$. oleifera using atomic absorption spectroscopy (AAS). The sodium concentration was found to be highest in crude methanol extract of $T$. bangwensis (MeCE 1) and crude methanol extract of $M$. oleifera (MeCE 2) followed by ethyl-acetate fractions of $T$. bangwensis (ETF 1) and $M$. oleifera (ETF 2) respectively while acetone fractions of T. bangwensis (ACF 1 and $M$. oleifera ACF 2) were low (Table 2). The potassium concentration of crude methanol extracts/fractions of $T$. bangwensis and M. oleifera were between $5.14 \mathrm{mg} / \mathrm{kg}$ to $14.63 \mathrm{mg} / \mathrm{kg}$ while magnesium concentration was found to be significantly low within the range of $0.02 \mathrm{mg} / \mathrm{kg}$ to $1.99 \mathrm{mg} / \mathrm{kg}$. The concentrations of the trace elements were low. The concentration of $\mathrm{Fe}$ in crude methanol extract of $M$. oleifera (MeCE 2) was found to be higher compared to other extracts and fractions. 


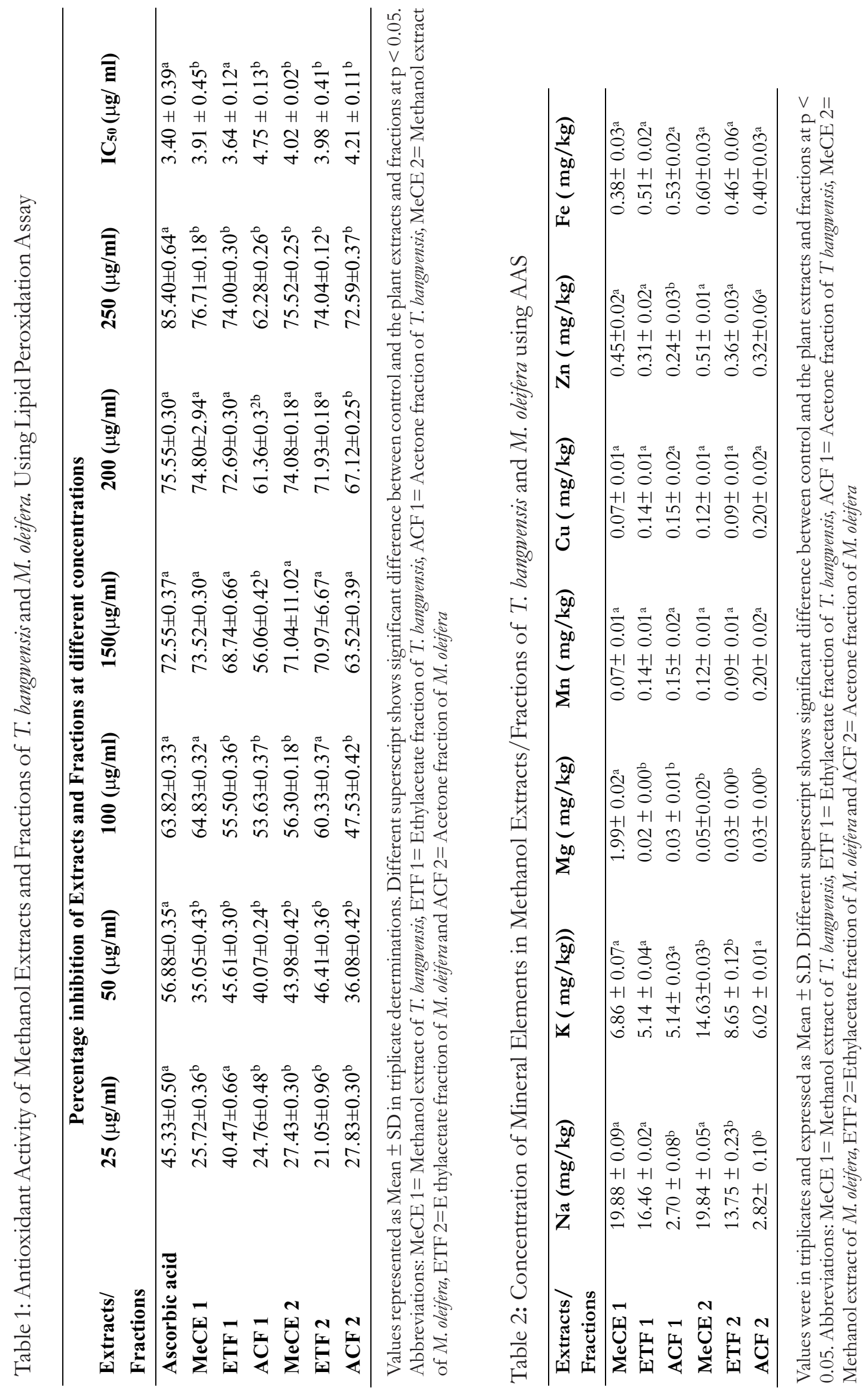




\section{Effects on Liver Biomarkers of Oxidative Stress}

Table 3 showed the result of the liver biomarkers of oxidative stress evaluated. The glutathione level was found to be low in the induced but untreated group but significantly increased in the induced and treated groups $(p<0.05)$ however the effect was higher in the group treated with ethylacetate fraction of $T$. bangwensis (ETF 1). Superoxide dismutase (SOD) activity decreased in the induced but untreated group but significantly increased in ethylacetate fraction of T. bangwensis (ETF 1) and acetone fraction of $M$. oleifera (ACF 2) treated groups respectively compared to other extracts/fractions. However the normal control group showed the highest SOD activity. Catalase activity significantly increased in the groups treated with the crude methanol extracts and fractions compared to the induced but untreated group. However, the effect was higher in ETF 1 compared to other induced and treated groups. There was elevated MDA level in the induced but untreated group. But after oral administration of crude methanol extracts/fractions of T. bangwensis and $M$. oleifera there was significant reduction in MDA level at $\mathrm{p}<0.05$.

\section{Effects on Liver Function Indices}

Table 4 showed that there was significant reduction in the aspartate aminotransferase (AST), alanine aminotransferase (ALT) and alkaline phosphatase (ALP) activity in the induced and treated groups compared to the induced but untreated group. Albumin level was found to be elevated in the induced but untreated group but significantly reduced in both the normal control group and the induced and treated groups however there was no significant difference between the induced but untreated group and crude methanol extracts of $T$. bangwensis and $M$. oleifera (MeCE 1 and MeCE 2) at $\mathrm{p}<0.05$. Total bilirubin, conjugated bilirubin and total protein levels were elevated in the induced but untreated group however there was significant reduction in the normal and induced and treated groups at $\mathrm{p}<$ 0.05 .

\section{Effects on the Lipid Profile}

Table 5 showed the effect of crude methanol extracts/fractions of T. bangwensis and $M$. oleifera on serum low density lipoprotein-cholesterol (LDL-c), high density lipoprotein-cholesterol (HDL-c), cholesterol (CHOL) and triglycerides (TRIG). The result revealed that these parameters were elevated in the induced but untreated group but significantly reduced in the induced and treated groups however the level of HDL-c was significantly elevated in the induced and treated groups compared to the induced but untreated group at $\mathrm{p}<0.05$. 


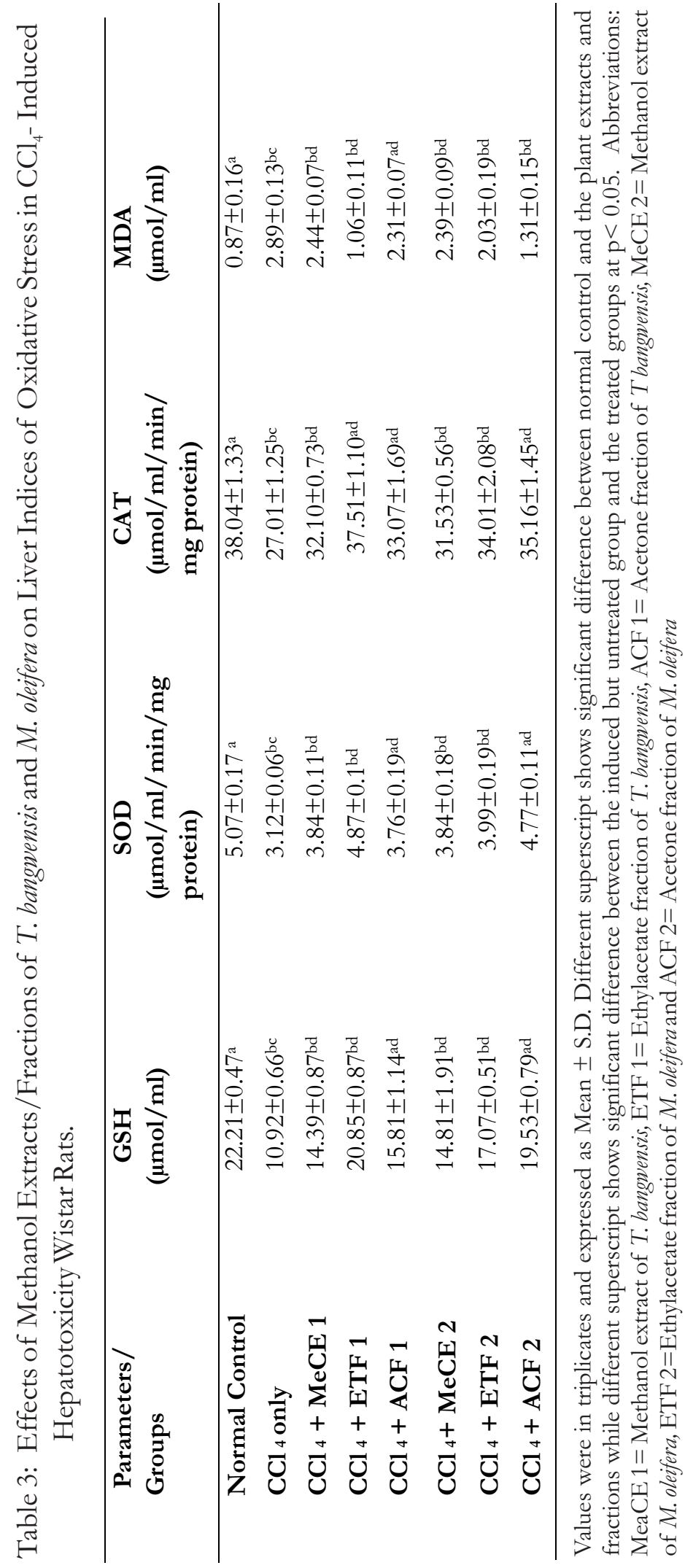




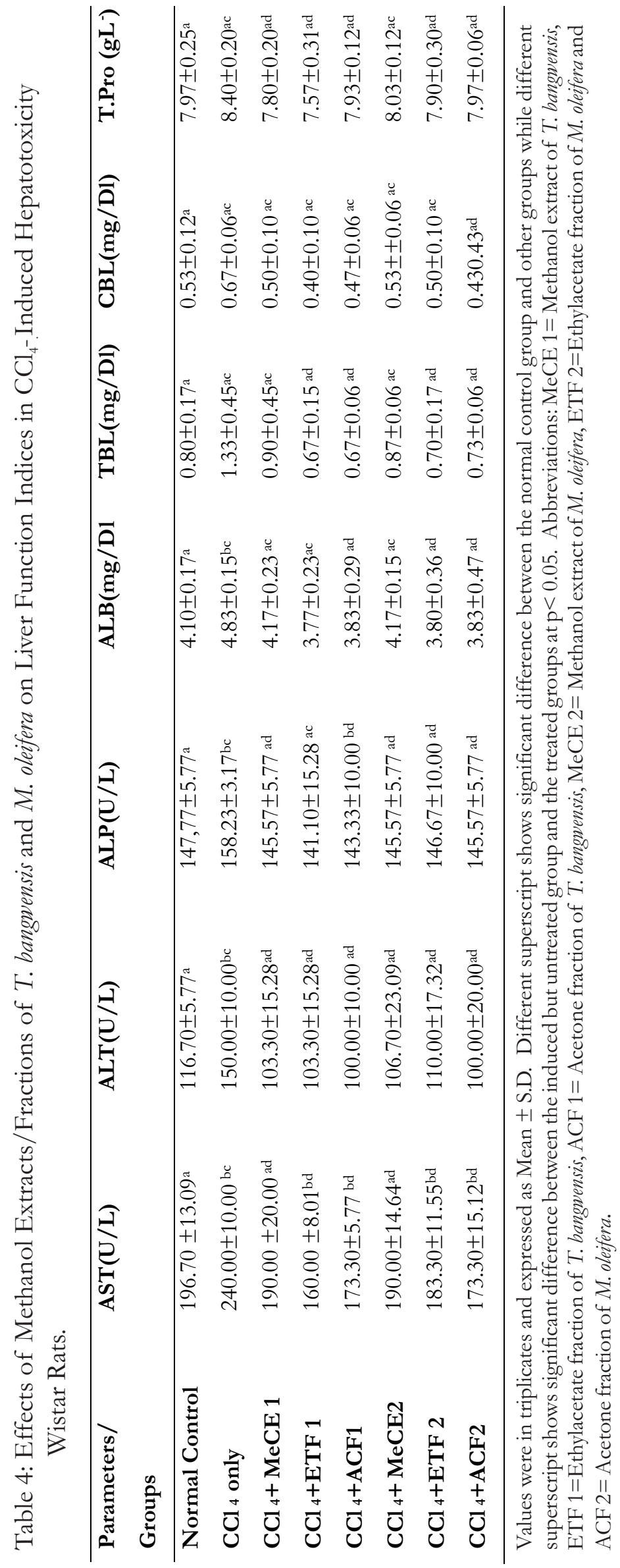


Table 5: Effects of Methanol Extracts/Fractions of T. bangwensis and M. oleifera on Lipid Profile in $\mathrm{CCl}_{4}$-Induced Hepatotoxicity Wistar Rats.

\begin{tabular}{|c|c|c|c|c|}
\hline $\begin{array}{l}\text { Parameters/ } \\
\text { Groups }\end{array}$ & LDL-c(mg/dL) & HDL-c(mg/dL) & Chol(mg/dL) & Trig (mg/dL) \\
\hline Control & $40.67 \pm 4.51^{\mathrm{a}}$ & $33.00 \pm 4.58^{\mathrm{a}}$ & $99.00 \pm 8.89^{a}$ & $80.00 \pm 5.57^{a}$ \\
\hline $\mathrm{CCl}_{4}$ only & $46.33 \pm 2.52^{\mathrm{bc}}$ & $23.67 \pm 2.52^{\mathrm{bc}}$ & $110.30 \pm 1.53^{b c}$ & $91.33 \pm 3.22^{\mathrm{bc}}$ \\
\hline $\mathrm{CCl}_{4}+\mathrm{MeCE} 1$ & $44.67 \pm 1.53^{\mathrm{ac}}$ & $32.00 \pm 3.00^{\mathrm{ad}}$ & $91.67 \pm 3.51^{\mathrm{ad}}$ & $75.33 \pm 6.51^{\mathrm{ad}}$ \\
\hline $\mathrm{CCl}_{4}+\mathrm{ETF} 1$ & $40.00 \pm 1.00$ ac & $29.33 \pm 0.58^{\mathrm{bc}}$ & $85.00 \pm 5.00^{\mathrm{ad}}$ & $71.67 \pm 2.89^{\mathrm{ad}}$ \\
\hline $\mathrm{CCl}_{4}+\mathrm{ACF} 1$ & $42.33 \pm 3.2 \mathrm{ac}$ & $29.67 \pm 5.03 \mathrm{bc}$ & $90.00 \pm 5.29^{\mathrm{ad}}$ & $75.33 \pm 4.04^{\mathrm{ad}}$ \\
\hline $\mathrm{CCl}_{4}+\mathrm{MeCE} 2$ & $41.67 \pm 3.51 \mathrm{ac}$ & $32.00 \pm 0.00$ ad & $90.00 \pm 5.00^{\mathrm{ad}}$ & $79.33 \pm 5.51^{\mathrm{ac}}$ \\
\hline $\mathrm{CCl}_{4}+\mathrm{ETF} 2$ & $40.67 \pm 7.77 \mathrm{ac}$ & $30.67 \pm 4.0$ ad & $87.33 \pm 11.59^{a d}$ & $74.33 \pm 4.04^{\mathrm{ad}}$ \\
\hline $\mathrm{CCl}_{4}+\mathrm{ACF} 2$ & $40.67 \pm 0.58^{\mathrm{ac}}$ & $30.33 \pm 1.16^{\mathrm{ad}}$ & $86.67 \pm 2.89^{\mathrm{ad}}$ & $74.33 \pm 4.04^{a d}$ \\
\hline
\end{tabular}

Values were in triplicates and expressed as Mean \pm S.D. Different superscript shows significant difference between the normal control group and other groups while different superscript shows significant difference between the induced but untreated group and the treated groups at $\mathrm{p}<0.05$. Abbreviations: MeCE $1=$ Methanol extract of T. bangwensis, ETF $1=$ Ethylacetate fraction of T. bangwensis, ACF $1=$ Acetone fraction of T. bangwensis, MeCE 2=Methanol extract of M. oleifera, ETF $2=$ Ethylacetate fraction of M. oleifera and ACF $2=$ Acetone fraction of M. oleifera

\section{Effects on Liver Histology}

The histopathological study of the liver tissues showed normal liver architecture in the normal control group but severe steatosis was observed in the group induced but untreated (Plate B). However after oral administration of crude methanol extracts/fractions of T. bangwensis and
M. oleifera normal hepatocyte distribution and no fatty changes were observed except in acetone fractions of T. bangwensis and M. oleifera where mild steatosis and portal vein congestion were observed respectively (ACF 1 and ACF 2; Plates E and $\mathrm{H}$ ) (Figure 1) 

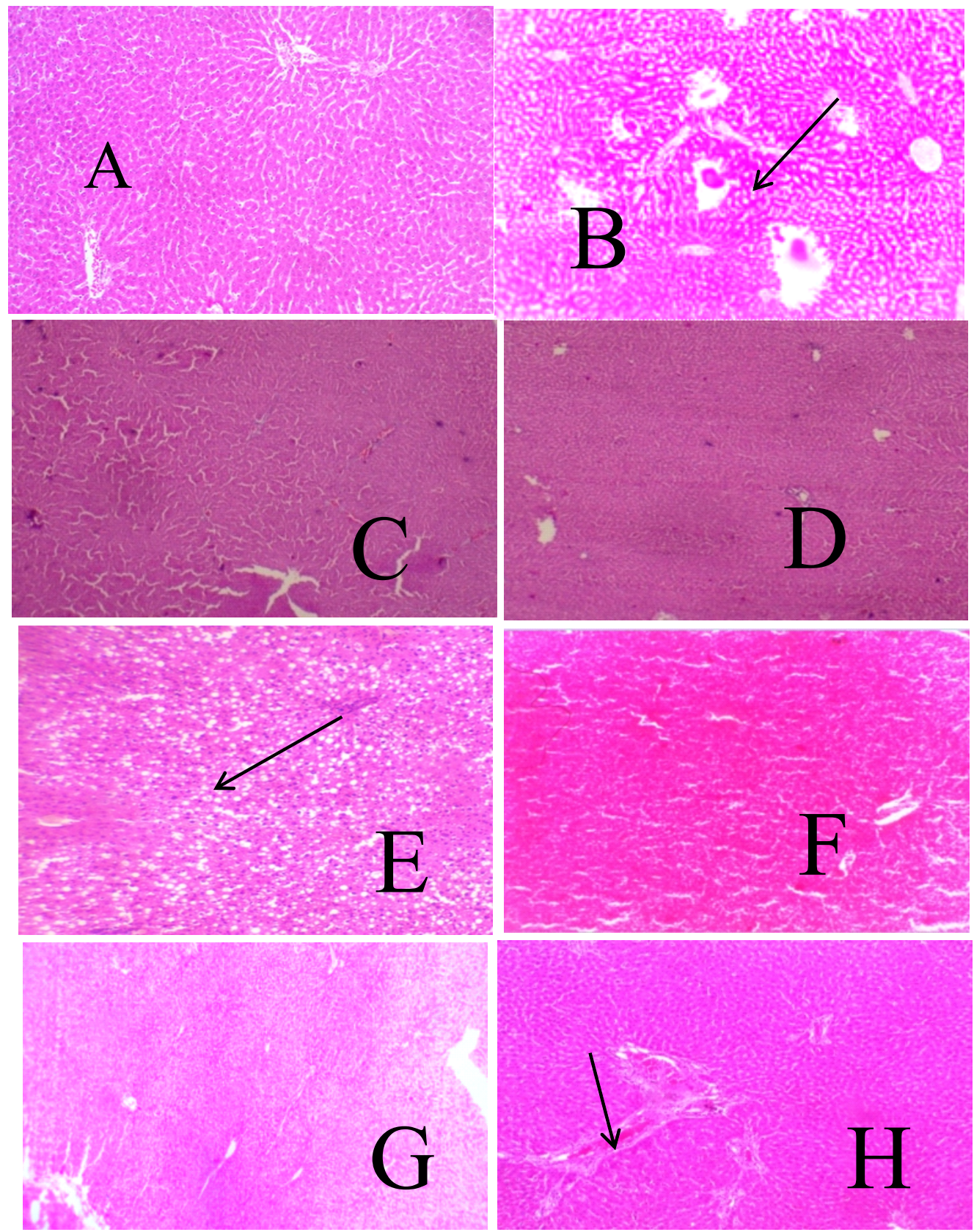

Figure 1: Histology Study of the Effect of Oral Administration of Crude Methanol Extracts/Fractions of T.bangwensis and M. oleifera on Liver Tissue (H \& E x 100).

Abbreviations: A : Normal hepatocyte distribution and no fatty changes (Normal control), B :Liver steatosis (Positive control), C: Normal hepatocyte distribution and no fatty changes (MeCE 1 group), D : Normal hepatocyte distribution and no fatty changes (ETF 1 group), E: Mild steatosis (ACF 1 group), F : Normal hepatocyte distribution and no fatty changes (MeCE 2 group), G : Normal hepatocyte distribution and no fatty changes (ETF 2 group), H : Normal hepatocyte distribution and no fatty changes (ACF 2 group) except for portal vein tract congestion. 


\section{DISCUSSION}

The present study design focussed on evaluating the mineral composition, antioxidant activity and hepatocurative potentials of crude methanol extracts/fractions of $T$. bangwensis and $M$. oleifera on carbon tetrachloride-induced hepatotoxicity in Wistar rats. The result in table 3 showed decreased superoxide dismutase and catalase activities in the group induced but untreated. These effects may be due to the accumulation of superoxide radicals and hydrogen peroxide generated through defective metabolic process (Srinivasan et al., 2007). There was as well a decreased glutathione level in the induced and untreated group which may be due to the extrusion of glutathione from the liver or increased utilization of glutathione for detoxification process while the MDA level increase was probably caused by the attack of lipid peroxyl free radicals generated through lipid peroxidation (Amat et al., 2010; Cho et al., 2013; Kepekci et al., 2013). Subsequently assessment of serum liver function indices as shown in table 4 showed elevated activities/levels of aspartate aminotransferase (AST), alanine aminotransferase (ALT) alkaline phosphatase (ALP), albumin, total protein, total and conjugated bilirubin respectively in the bloodstream as observed in the induced and untreated group (Nkosi et al., 2005; Mohamed et al., 2009; Dominic et al., 2012; Osman, 2013). The elevated serum activity of ALT, AST and ALP may be due to hepatocellular necrosis which caused increase in the permeability of the cell membrane resulting in the release of hepatic enzymes or the stimulation of lipid peroxidation and depletion of antioxidant reservoirs while increased ALP activity indicates increased alkaline phosphate biosynthesis in response to biliary obstruction (Mauro and Renze, 2008; Nalk, 2010; Sharma and Pandey, 2010)). The serum elevated levels of total and conjugated bilirubin could have resulted from decreased uptake and conjugation of bilirubin by hepatocyte dysfunction or decrease secretion from the liver or obstruction of the bile acids (Sharma et al., 2009). Trace elements generally act as co-factors in a number of antioxidant metalloenzymes. Selenium and iron are co-factors in glutathione peroxidase and catalase respectively while superoxide dismutase contains copper, zinc or manganese as cofactors. These trace elements have been reported to be critical in protecting internal cellular constituents from oxidative damage by helping to improve the activities of the liver antioxidant enzymes. For instance zinc has been reported to control cell proliferation, differentiation and apoptotic/necrotic cell death as well as possessing anti-hepatotoxic effect (Rogalska et al., 2011). In contrast deficiency of these trace elements especially zinc and copper cause oxidative stress and damage to biological molecules and membranes (McDowell et al., 2007). Therefore the hepatocurative effect observed in this study could be due to the presence of copper and zinc and/or strong antioxidant activity exhibited by crude methanol extracts/fractions of the plants which may be attributed to the presence of phytochemical compounds inherent in them (Ihegboro et al., 2018). The increased levels of triglycerides, cholesterol and low density lipoprotein as shown in table 5 may be due to defective metabolism of phospholipids, increased biosynthesis from acetate, increased fatty acid esterification, inhibition of fatty acid betaoxidation or decreased excretion of cellular lipids (Weber et al., 2003; Fernandez and West, 2005;). However the lipid-lowering potential of the methanol extracts/fractions of the plants may be due to the chelating activity of phytochemicals with the by-products from $\mathrm{CCl}_{4}$ metabolites, thereby minimizing the adverse effect of $\mathrm{CCl}_{4}$ on the liver (Chungma et al., 2007; Iheanacho et al., 2008; Singh and Rao, 2008) or presence of magnesium level in the plants' extracts/fractions as magnesium has been shown to have strong biological plausibility in the reduction of lipid parameters in cardiovascular disease (Bo and Pisu, 2008). Finally the accumulation of fat in the liver as observed in the group induced but untreated indicates defective lipid metabolism and this causes impaired blood flow through the liver thereby resulting in onset of hepatic hypertension (Shannon, 2017) however histopathology study of the liver section administered with methanol extracts/fractions of T. bangwensis and M. oleifera showed attenuation.

\section{CONCLUSION}

The result of the present study showed that $T$. bangwensis and $M$. oleifera ameliorated the effects of carbon tetrachloride-induced hepatotoxicity in Wistar rats. Furthermore, the hepatocurative effect observed could be due to the antioxidant 
properties and mineral composition of the plants however $T$. bangwensis showed higher hepatocurative effect compared to M. oleifera.

\section{ACKNOWLEDGEMENT}

We want to sincerely appreciate the technical efforts of Mr. Sunday Adenekan, Department of Biochemistry, University of Lagos, Mr. Maicah Chijoke, Department of Pharmacology, University of Lagos and Miss Gladys Ihegboro and Ikuemelo Israel, Department of Biochemistry and Forensic Science, Nigeria Police Academy, Wudil, Kano.

\section{REFERENCES}

Adewusi. E. A. and Afolayan. A. J. 2010. A review of natural products with hepatoprotective activity. Journal Medicinal plants Research, 4:1318-1338.

Ajiboye, T. O. 2010. In vivo antioxidant potential of $P$. thomiigsi (Schum) leaves studies in hepatic marker enzyme, antioxidant system and dry detoxifying enzyme on lipid peroxidation in experimental rats. Toxicology, 30(1):55-62.

Amat, N. Upur, H and. Blazekovic, B. 2010. In vivo hepatoprotective activity of the aqueous extract of Artemisia absinthium L against chemically and immunological induced liver injuries in mice. Journal Ethnopharmacology, 131:478-484.

Anwar, F and Rashid, U. 2007. Phytochemical characteristics of Moringa oleifera seeds and seed oil from a wild provenance of Pakistan. Pakistan Journal of Biology, 39: 1443-1453.

Bo, S. and Pisu, E. 2008. Roles of dietary magnesium in cardiovascular disease prevention, insulin-sensitivity and diabetes. Current opinion in Lipidology, 10(1): 50-56.

Buege, J. A. and Aust, S. D. 1978. Microsomal lipid peroxidation methods. Ensymology, 52: 302-310.

Cho, B. O. Ryu, H. W. So, Y. Jin, C. H. Baek, J. Y. Park, K. H. Byun, E. H. and Jeong, I. Y. 2013. Hepatoprotective effect of 2,3dihydrosilybin on $\mathrm{CCl}_{4-}$ induced liver injury in rats. Food Chemistry, 138: 107115.

Chungma, P. Yusizhou, Y. and Youngsu, S. 2007.
Hepatotoxicity effect of dandelion (Taraxacum officinale) in acute liver injury induced by $\mathrm{CCl}_{4}$ in Sprague Dawley rats. FASEB Journal, 21: 862-868.

Dominic Amalraj, A. Parkari, C. Murugalash, K. and Dhanaraj, T.S. 2012. Hypolipidemic activity of $C$. roumthus on $\mathrm{CCL}_{4}$ induced dyslipidemia in rats. Asian Journal Pharmacology Technology, 2(2):51-53.

El-Sayed, Y.S. Labda, M.A. Hasinin, M. and Neoman, S.A. 2015. Chicory (Ochorium inybus $L$ ) root extract regulate the oxidative status and antioxidant gene transcripts in $\mathrm{CCl}_{4}$ induced hepatotoxicity PLoS One, 10(3):eo121549.

Fernandez, M. L. and West, K. L. 2005. Mechanisms by which dietary fatty acids modulate plasma lipids. Journal of Nutrition, 135(9):2075-2078.

Ginanaprakash, K. Madhusudhama, O. C. Ramkarth, S. Alagusumdaram, M. Tiruvengedarajan, V. S and Angala, P. S. 2010. Aqueous extract of Flacouria indica prevents $\mathrm{CCl}_{4}$ induced hepatotoxicity in rats. International Journal Biology Life. Science, 6:51-55.

Grish, C. Komer, B. C. Jayanthi, S. Rao, K. L. Rajesh, B. and Pradhan. S. C. 2009. Hepatoprotective activity of six polyherbal formulation in $\mathrm{CCL}_{4}$ induced liver toxicity in mice. Indian Journal ExperimentalBiology, 47:257-263.

Iheanacho, K. M. E. Udebani, A. C. and Ihegboro, G. O. 2008. Phytochemistry and effect of aqueous leaf extract of mistletoe (Tapinanthus bangwensis) on serum glucose and cholesterol concentrations in normoglycemic rats. Nigeria Journal Biochemistry Molecular Biology, 23(2): 35-39.

Ihegboro, G.O, Ononamadu, C.J, Afor, E and Odogiyan D.G. 2018. Cytotoxic and hepatocurative effects of aqueous extract of Tapinanthus Bangwensis against paracetamol-induced hepatotoxicity. Journal of Evidence-Based Integrative Medicine, 27:1-7.

Kepekci, R. A. Palat, S. Celik, A. Bayat, N. and Saygideger, S. D. 2013. Protective effect of Spirulina platensis enriched in phenolic compounds against hepatotoxicity induced by $\mathrm{CCl}_{4}$. Food Chemistry, 141: 1972- 
1979.

Khan, M.R. Rizvi, W. Khan, G.N. Khan, B. A. and Shaheen, S. 2009. Carbon tetrachloride induce nephrotoxicity in rats, protective role of Digera maricana. JournalEthnopharmalogy, 122:91-99.

Kumar. T. and Chandrashekark, K. S. 2011. B. purpurea Linn. A review of ethnobotany, phytochemical and pharmacological profile. Research Journal Medicinal Plants, 5:420-431.

Mauro, P and Renze, B. 2008. Fundamentals of clinical chemistry. $6^{\text {th }}$ Ed. 325.

McDowell, L. R. Nancy, W. Rachel, M. and Tara, F. 2007. Vitamins, minerals functioning as Antioxidants with supplementation consideration. Florida Ruminant Nutrition Symposium. Best Western Gateway Grand, Florida. Pp 1-16.

Million, L. Abay, M and Solomon, M.A. 2019. Acute and subacute toxicity of methanol extract of Syaygiym guineense leaves on the histology of the liver and kidney and Biochemical composition of Blood in rats. Evidence-based Complementary Alternative Medicine, 2019: 1-15.

Mohamed, R. A. Ramadan, R. S. and Ahmed, L. A. 2009. Effect of substituting pumpkin seed protein isolate for case in non-serum liver enzymes, lipid profile and antioxidant enzymes in $\mathrm{CCL}_{4}$ in toxicated rats. Advance Biological Research, 3(1-2):9-15.

Nalk, P. 2010. Biochemistry, $3^{\text {rd }}$ Ed. Panama Jaypee publishers Ltd. Pp 138-141, 565

Nikkon, F. 2003. In Vitro antimicrobial activity of the compound isolated from chloroform extract of Moringa oleifera Lam. Pakistan Journal of Biological Science, 22: 1888-1890.

Nkosi, C. Z. Opoku, A. R. and Terblanche, S. E. 2005. Effect of pumpkin seed protein isolate in the activity levels of certain plasma enzymes in $\mathrm{CCL}_{4}$ induced liver injury in low protein fed rats. Phototherapy Research, 19(4):341-345.

Onyekal, T. U., Chinedu, O. G. and Fred, A. C. 2013. Phytochemical screening and investigation of antibacterial activities of various fractions of the ethanol leaves extract of Moringa oleifera Lam. Journal of Pharmaceutic Chemistry Biological Science, 3(3): 962-973
Osman, N. N. 2013. The role of antioxidant properties of celery against lead induced hepatotoxicity and oxidative stress in irradiated rats. Arab Journal Nuclear Science and Application, 46(1):339-346.

Pallwell, R. 2011. Elucidation of free radical scavenging and antioxidant activity of aqueous and hydroethanol extracts of Moringa oleifera pods. Research Journal of Pharmaceutical Technology, 4: 566-571.

Rogalska, J. Pilat-Marcinikiewicz, B. and Brzoska, M. M. 2011. Protective effect of $\mathrm{Zn}$ against cadmium hepatotoxicity depends on this bio element intake and level of cadmium exposure, a study in a rat model. Chemi Biologi interact, 193: 191-203.

Shannon, M. 2017. Pathology of the liver and Billary tract-2: Developmental, Circulatory and Metabolic disorders. Developmental Anomalies. Pp 1-23.

Sharma, A. Sharma, V. and Kansa, L. 2009. Therapeutic effects of Allium sativum on lead-induced biochemical changes in soft tissues of Swiss albino mice. Pharmacognosy Management, 5(20):364-371.

Sharma, V. and Pandey, D. 2010. Protective role of Tinospora cordifolia against lead-induced hepatotoxicity. Toxicological International, 17(1):12-17.

Singh, R. and Rao, H.S. 2008: Hepatoprotective effect of the pulp/seed of Aegle marmelos correa extract against carbon tetrachloride induced in liver damage in rats. International Journal Green Pharmacolgy, 2(4): 232-234.

Sinha, M, Das, D. K, Dactas, S, Gosh, S and Dey, S. 2011. Amelioration of ionizing radiation induced lipid peroxidation in mouse liver by $M$. oleifera Lam leaf extract. Journal of ExperimentalBiology, 50(3): 209-215.

Si-Tayeb, K. Lemuigre, F. P. and Duncan, S. A. 2010. Organogenesis and development of the liver. Developmental Cell,18:175-189.

Soylak, M, Tuzen, M. and Hayatisari, I. N. 2004. Comparison of microwave, dry and wet digestion procedure for the determination of trace metal contents in space samples produced in Turkey. Journal Food Drug Analysis, 12(3): 254-258.

Stevens, C. O., Ugese, F. D. and Baiyeri, K. P. 2015. Utilization potentials of Moringa oleifera in 
Nigeria: A preliminary Assessment. International Letters of Natural Science, 40: 30-37.

Srinivasan, R. Chandrasekar, M.J.N. Nanjan, M.J. and Suresh, B. 2007. Antioxidant activity of Caesalphia digyna. Journal Ethnopharmacology, 113: 284-291.

Wagh, A. E. Yeotkar, U. S. Nimbhorker, M. G. Deshmukh, T. A. and Patil, V. R. 2010. Hepatoprotective activity of Marbor trisus (L). Orient Pharmacology Experimental Medicine, 10:111-115.

Walter, A. 2011. Antibacterial activity of Moringa oleifera and Moringa stenopocula methanol and hexane seed extracts on bacteria implicated in water-borne diseases. African Journal of Microbiology, 51: 153-157.

Weber, L. W. Boll, M. and Stampfl, A. 2003. Hepatotoxicity and mechanism of action of haloalkanes, $\mathrm{CCl}_{4}$ as a toxicological model. Critical Review Toxicology, 33

Xu, L. Gao, Y. and Wang, Y. 2011. Myrica rubra extracts protect the liver from $\mathrm{CCl}_{4}{ }^{-}$ induced damage. Evidence-Based Complement Alternative Medicine, 2011: 518302. 